\title{
Art and psychosis: Elements of psychopathology in the work of Edgar Allan Poe. The
} case of tale tell heart

\author{
Evangelos Fradelos
}

Psychiatric Department, Athens General Hospital of Chest Diseases, Athens Greece

University of Thessaly, Larisa, Greece

\begin{abstract}
.
1. Since the depths of time up until nowadays arts can one say that reveals our unconscious, mental state, depicts our hopes and fears as well as shapes our expectations. In literature we can say that mental illness and writers are accompanied each other since ages as they write from a personal perspective or a socially conscious one. This paper is to reveal elements of psychiatric symptomatology in the main character and narrator of The tale tell heart of Poe and to answer what types of symptoms is the narrator experiencing. In this study a qualitative descriptive methodology is employed in order to answer the main research question. The main character of the novel is experiencing symptoms such as auditory hallucinations, delusional ideas and more. The behavior and mental state of the narrator is escalating through the text and finally commits an unspeakable crime. By examine the depictions of psychiatric illness in the literature and arts in general of a specific period of time enlights the beliefs and the perception that people of such time had on mental illness and patients in such way help us to understand the evolution of stigma and stigmatizing behaviors through time
\end{abstract}

